PERSONALITY AND CHARACTER

Two of a kind or distant relatives? A multimethod investigation of the overlap between personality traits and character strengths

This manuscript is currently under review.

Version 2: September $9^{\text {th }} 2022$

Willibald Ruch ${ }^{1}$

Valentina Vylobkova ${ }^{1}$

Sonja Heintz ${ }^{12}$

${ }^{1}$ Department of Psychology, University of Zurich, Zurich, Switzerland

${ }^{2}$ School of Psychology, University of Plymouth, Plymouth, United Kingdom

Correspondence concerning this article should be addressed to: Willibald Ruch,

Section on Personality and Assessment, Department of Psychology, University of Zurich, Binzmühlestrasse 14/7, 8050 Zurich, Switzerland. E-mail: w.ruch@psychologie.uzh.ch.

Acknowledgements

We would like to thank Alois Angleitner and Sonja Loske for their help in collecting and preparing the data.

Funding statement: This publication was supported by the Swiss National Science Foundation (grant number 172’723).

Conflict of interest statement: Willibald Ruch is a Senior Scientist for the VIA Institute on Character.

Author contributions: WR designed the study, VV and SH conducted the data analyses and drafted the manuscript, and all authors contributed to revisions of the manuscript. 
PERSONALITY AND CHARACTER

\begin{abstract}
Allport's distinction of personality devaluated (personality) and personality evaluated (character) raised the question if character is redundant with personality, which still remains open today. The present study hence compares the Five-Factor Model of personality and the VIA-classification of character strengths across two methods (self- and peer-reports) and across two levels of abstraction (domains/factors and scales/facets). A sample of 152 participants and 152 peer-raters completed the NEO-Personality Inventory Revised and the VIA Inventory of Strength. Personality and character assessed with these inventories were found to strongly overlap, yet the different operationalizations were rarely redundant (except for three personality facets). Multitrait-multimethod analyses mostly supported the convergent and discriminant validity of personality and character. Interpersonal strengths (e.g., teamwork) and abstract character factors lacked discriminant validity to personality facets. The present investigation contributes to a better understanding of the interplay between personality and character and provides an impetus for future research on the "virtue gap" between devaluated and evaluated personality traits.
\end{abstract}

Keywords: Five-Factor Model of personality, Big Five, character strengths, virtues, personality facets, positive psychology 


\section{PERSONALITY AND CHARACTER}

Two of a kind or distant relatives? A multimethod investigation of the overlap between personality traits and character strengths

Personality and character represent the core temperamental individual differences between people (Allport, 1921). The meaning and evaluation of these constructs varied according to the epoch of the study and the societal circumstances (e.g. Nicholson, 1998). Nevertheless, the functions of both constructs are similar: To describe individual differences between people, and to predict behavioral outcomes (Ozer \& Benet-Martínez, 2006; Peterson \& Seligman, 2004). Allport (1927) postulated: “There is likewise confusion between personality devaluated and personality evaluated, that is, between personality and character" (p. 285). He also pointed out the ambiguity and context dependance of "moral traits" (Allport, 1927, p. 285), and consequently suggested that personality should be studied in psychology, while character rather belonged to social ethics (Allport, 1921; Ruch \& Stahlmann, 2020). Probably due to this distinction, psychology focused on the more 'neutral' personality traits and psychological disorders rather than positively evaluated personality characteristics (Peterson \& Seligman, 2004; Seligman \& Csikszentmihalyi, 2000). Due to the renewed interest in character within the positive psychology movement and the VIA-classification of character strengths and virtues (VIA-CSV, Peterson \& Seligman, 2004), the question on what distinguishes personality and character has gained new attention. The present study seeks to add new insights to this question, by investigating the overlap of the most frequent approaches to personality and character, namely the Five-Factor Model of personality (FFM) and the VIA-CSV.

While several conceptualizations of personality exist, the most prominent personality model for a while entails five broad factors, and is most commonly referred to as the Five Factor Model (FFM) of personality. While its development is mainly rooted in psycholexical studies of trait terms (where Goldberg in 1990 initially used the label "Big Five") it was also recovered from questionnaire data. There, the NEO-PI is an influential instrument where each 


\section{PERSONALITY AND CHARACTER}

of the five broad traits (i.e., extraversion, neuroticism, openness to experience, agreeableness, and conscientiousness) are measured by of six facets per domain (e.g., Costa \& McCrae, 1992). The five-factor structure was found to be valid and rather stable in many languages and cultures (e.g., Costa \& McCrae, 1992; Costa et al., 2019). Recent studies also pointed to the added value of investigating the 30 FFM facets (six for each of the five traits; e.g., Anglim, \& Grant, 2014).

While the FFM has been extensively studied, psychological research on character comparably is still rather scarce. One of the broadly studied conceptualizations of character is the VIA-CSV classification. Peterson and Seligman (2004) analyzed the broad literature on morally evaluated personality characteristics and suggested a classification of 24 character strengths and six core virtues (VIA-CSV). The character strengths are conceptualized to be inherently morally valued, universal, trait-like, and to influence behaviors, thoughts and feelings, among other criteria. The 24 character strengths are grouped under six universal core virtues (wisdom and knowledge, courage, humanity, justice, temperance, and transcendence) and are seen as distinct ways to express each virtue. When factor-analyzing the 24 character strengths scales, usually three to five high-order factors are found (for an overview, see McGrath, 2014). For both simplicity and consistency, we use the term "personality" to denote the FFM as measured by the NEO-PI-R, and we use the term "character" for the VIA-CSV.

\section{The Overlap between Personality and Character}

If Allport's assertion (1927) that character is personality evaluated applies, we would expect to find both an overlap between character strengths (e.g., the VIA-CSV) and personality traits (e.g., the NEO-PI-R variant of the FFM) as well as a gap due to the evaluative nature of the character terms. To date four empirical studies supported these notions using the NEO-PI-R domains and facets and the VIA-CSV scales and factors (Dametto \& Porto Noronha, 2021; Macdonald et al., 2008; McGrath et al., 2020; Noftle et al., 2011). Employing multiple regression analyses, the FFM traits predicted between $3 \%$ and 


\section{PERSONALITY AND CHARACTER}

59\% in the individual VIA-CSV factors (Macdonald et al., 2008). Noftle et al. (2011) found that the FFM domains explained on average 33\% variance in the 24 character strengths (range $14-46 \%$ ), and the FFM facets explained on average $40 \%$ variance in the 24 character strengths (range 30-50\%). In the most extensive investigation to date, McGrath et al. (2020) found a mean explained variance of the FFM facets in the character strengths from 42-48\%. Recently, Dametto and Porto Noronha (2021) found predictions by the FFM domains in the character strengths ranging from $9-34 \%$ in adolescents. Overall, these studies found on average that the FFM domains and facets could predict around 30-40\% variance in the VIA-CSV scales and factors.

\section{Aims of the Study}

The aims of the present study are to further explore the relationship between personality and character. Our study first seeks to replicate the previous findings on the overlap of character strengths and the FFM domains and facets (Dametto, \& Porto Noronha, 2021; Macdonald et al., 2007; McGrath et al., 2020; Noftle et al., 2011). Second, as past research relied on selfreports, our study explores the overlap between personality and character in peer-reports. Third, we employed for the first time the standard measures for character strengths (the VIAIS) as well as the standard measure for the FFM (NEO-PI-R) with the same participants. Fourth, we look both at how personality predicts character (in line with previous studies), but also at how well character can predict personality.

A fifth aspect to be considered when evaluating the correlations between character and personality traits is the level of abstraction. We seek to extend the previous findings by systematically comparing the more abstract higher-order constructs (3-5 VIA-CSV factors and 5 FFM domains) and the more specific lower-order constructs (24 VIA-CSV scales and 30 FFM facets). Thus, we consider both comparisons at different levels and with different methods to determine the overlap between personality and character in more detail and more comprehensively than previous studies. 


\section{Method}

\section{Participants}

Initially, a convenience sample of 163 participants from a large industrial city in Germany recruited via personal contacts completed the self-reports. Four participants who indicated to be $<18$ years were excluded from the analysis. Every participant was asked to invite a family member, a friend, or another close person to complete the peer-report. A total of 160 participants completed the peer-reports. Three participants who indicated to be $<18$ years were excluded from the analysis. Also, only participants were retained who provided both self-reports and peer-reports, resulting in a final sample of 152 participants.

The mean age of the participants who completed the self-reports was 33.06 years $(S D$ $=10.37)$ and ranged from $18-66$ years. The gender ratio was relative balanced ( $59 \%$ female, $41 \%$ male). Most (63\%) of the participants were employees and $20 \%$ were university students. The sample was rather well educated: $35 \%$ of the participants had a university entrance qualification and $28 \%$ had a university degree.

The gender ratio of the participants who completed the peer-reports was $41 \%$ males and $59 \%$ females. The mean age of the sample was 33.67 years $(S D=10.33)$, and ranged from 18-61 years. The peer-raters were also well educated: $34 \%$ had a university entrance qualification and 24\% participants had a university degree. Most (67\%) were employees and $19 \%$ were university students. Most of the peer-reports were completed by a significant other, like the spouse $(32 \%)$, partner $(24 \%)$, or boyfriend/girlfriend $(26 \%)$. The peers knew the study participants between 4 months and 50 years $(M=12.08$ years, $S D=11.58)$ and rather well $(M$ $=8.30, S D=0.71$, range 7-9 on a 9-point Likert scale from 1 very little to 9 very good).

\section{Instruments}

Character strengths were assessed with the German self- and peer report version (Ruch et al., 2010) of the VIA-IS (Peterson et al., 2005). The VIA-IS is a 240-item measure, which consists of 24 character strength scales, with 10 items for each (scale overview in 
PERSONALITY AND CHARACTER

supplementary Tables S1-S2). The response scale is a 5-point Likert-scale from 1 very much unlike me to 5 very much like me.

To assess the personality traits of the FFM, we used the German self- and peer-report version (Ostendorf \& Angleitner, 2004) of the NEO-PI-R (Costa \& McCrae, 1992). The NEO-PI-R is the standard inventory to assess the FFM and its facets (six per factor; scale overview in supplementary Tables S3-S4). The NEO-PI-R consists of 240 items, with 48 items for each personality factor (and 8 items for each facet).

\section{Procedure}

All participants completed the questionnaires in paper-pencil surveys, which they received via mail or personally from the researchers. All participants provided written informed consent, and the study was conducted in line with the local ethical guidelines. As reimbursement, participants received personal feedback on their results. Participants who were psychology students also received course credits for their participation. The NEO-PI-R was presented first, followed by VIA-IS. The peers were invited to complete the ratings of one person who also submitted self-reports.

\section{Statistical Analyses}

The data was analyzed with IBM ${ }^{\circledR}$ SPSS ${ }^{\circledR}(25.0 .0 .1)$. First, missing values of seven participants were analyzed (range $=5.4-20.6 \%, M d n=10.4 \%)$. Little`s MCAR tests was always non-significant, suggesting all missings were completely at random (though this test is not without limitations; Rhoads, 2012). Thus, they were imputed using the expectation maximization algorithm. This resulted in 152 complete data sets with self- and peer-reports that were used for further data analysis.

To compute the five NEO-PI-R and five VIA-IS factors, two principal component analyses with varimax factor rotation were conducted, in line with previous research (Ruch et al., 2010). The 30 NEO-PI-R facets and the 24 VIA-IS scales resulted in five components each, and the factor scores for each of these five extracted components were saved and used 


\section{PERSONALITY AND CHARACTER}

in the analyses (factor solutions and congruences are shown in Tables S7-S8). The reliabilities of the VIA-IS factors were computed on the basis of the strengths with the highest loadings on each factor. The reliabilities of the NEO-PI-R factors were computed on the basis of the six facets corresponding to the each of the factors.

Standard multiple regression analyses were conducted separately for the self- and peer-reports. The resulting $R^{2}$ values were then compared to Cronbach's alpha as the lower bound of reliability. To support the distinction between character and personality, $R^{2}$ (i.e., the overlap, the amount of variance explained by the predictors) should be lower than Cronbach's alpha (i.e., least amount of true variance in the scale). Additionally, the multitraitmultimethod (MTMM) correlation matrices between the VIA-IS scales and factors and the NEO-PI-R facets and factors, respectively, were computed. Convergent validity is indicated by self-peer convergence (i.e., correlation between the same scale in self- and peer-reports) of at least .30 (indicating a large effect; Gignac \& Szodorai, 2016). We computed discriminant validity as a median over absolute values of all self-peer correlations with the facets/scales/factors across the two methods. Discriminant validity is indicated by self-peer convergence being greater than the correlations with the other facets, scales, or factors across the two methods (see Campbell, \& Fiske, 1959).

\section{Results}

Descriptive statistics of the study variables are shown in the supplementary Tables S1-S4. Table 1 shows the overlap of the NEO-PI-R facets and factors with the VIA scales and factors. The overlap was very large with the 24 VIA scales $(M d n=56 \%$ in self-reports and $M d n=58 \%$ in peer-reports) and medium to large with the 5 VIA factors ( $M d n=35 \%$ in self-reports and $M d n=42 \%$ in peer-reports). The median proportion of the true-score variance in NEO-PI-R facets accounted for by the VIA-IS scales was 75\% (range 37-100\%) for self-reports and 72\% (range 49-100\%) for peer-reports. A similar pattern occurred for the NEO-PI-R factors. The proportion of the explained true-score variance was always higher on 


\section{PERSONALITY AND CHARACTER}

the lower level than on the higher level of abstraction. The median proportion of the truescore variance in VIA-IS scales accounted for by NEO-PI-R facets was 77\% (range 43-93\%) for self-reports and 79\% (range 45-94\%) for peer-reports. Similar patterns were found for the VIA factors (for details, see supplementary Tables S5-S6). Importantly, the VIA factors and scales explained less than the true-score variance; hence, character was not sufficient to explain the variability in personality. Exceptions were found for three facets in which the VIA scales explained as much or more variance: N5 Impulsiveness (self-reports), O6 Values (peerreports), and C1 Competence (peer-reports).

Supplementary Tables S5-S6 further contain the correlations between each NEO-PI-R facet and factor and the VIA scales and factors. N5 Impulsiveness showed large negative correlations with the strengths of prudence and self-regulation, O6 Values correlated positively with fairness and leadership, and C1 Competence correlated strongly and positively with judgment, perspective, and perseverance. As the VIA-strengths are based on emotional stability (Peterson \& Seligman, 2004), the scales and factors showed strong negative relationships with neuroticism and its facets. Investigating the multitrait-multimethod matrix, convergent validity (range .33-.67) was supported for all NEO-PI-R facets and factors. Importantly, self-peer convergence was always higher than the corresponding correlations with the VIA scales and factors, supporting discriminant validity for all scores of the NEO-PIR.

Table 2 shows the overlap of the VIA scales and factors with the NEO-PI-R facets and factors. The overlap was again very large with the 30 NEO-PI-R facets ( $M d n=58 \%$ in selfreports and $M d n=64 \%$ in peer-reports) and medium to large with the 5 VIA factors ( $M d n=$ $37 \%$ in self-reports and $M d n=45 \%$ in peer-reports). For all VIA scales and factors, the NEOPI-R explained less than the true-score variance; that is, personality was not sufficient to explain the variability in character. The lowest overlaps were found for the character strength spirituality and other theological strengths, which were not well captured by the NEO-PI-R. 
PERSONALITY AND CHARACTER

We also computed adjusted $R^{2}$ values (supplementary Tables S5-S6), yielding very similar results.

Investigating the multitrait-multimethod matrix (for details, see supplementary Tables S9-S12), the self-peer convergence was always higher than .30, except for perspective (.29), honesty (.26), and leadership (.29), generally supporting convergent validity. In contrast to the NEO-PI-R findings, self-peer convergence was not always higher than the corresponding correlations with NEO-PI-R: 8 of the 24 VIA-IS scales (perspective, honesty, social intelligence, teamwork, fairness, leadership, forgiveness, and humility) and 4 of the 5 VIA-IS factors (all except for theological strengths) correlated slightly higher with one or more of the NEO facets (and sometimes also NEO factors) than their self-peer convergence. Thus, discriminant validity was supported for $2 / 3$ of the VIA-IS-scales, but for only $1 / 5$ VIA-IS factors. 


\section{PERSONALITY AND CHARACTER}

Table 1

Cronbach's alpha and $R^{2}$ between the NEO-PI-R facets and factors and the VIA-IS scales and factors in Self- and Peer-Reports, and Convergent and Discriminant Correlations across Selfand Peer-Reports

\begin{tabular}{|c|c|c|c|c|c|c|c|c|c|}
\hline & \multicolumn{3}{|c|}{ Self-reports } & \multicolumn{3}{|c|}{ Peer-reports } & \multicolumn{3}{|c|}{ Self×peer-reports } \\
\hline & Alpha & $\begin{array}{l}\text { VIA } \\
\text { scales }\end{array}$ & $\begin{array}{l}\text { VIA } \\
\text { factors }\end{array}$ & Alpha & $\begin{array}{l}\text { VIA } \\
\text { scales }\end{array}$ & $\begin{array}{l}\text { VIA } \\
\text { factors }\end{array}$ & $\begin{array}{l}\text { Conver- } \\
\text { gence }\end{array}$ & $\begin{array}{l}\text { VIA } \\
\text { scales }\end{array}$ & $\begin{array}{l}\text { VIA } \\
\text { factors }\end{array}$ \\
\hline \multicolumn{10}{|l|}{ NEO-PI-R facets } \\
\hline N1: Anxiety & .85 & .56 & .31 & .82 & .59 & .27 & .58 & .38 & .30 \\
\hline N2: Angry Hostility & .71 & .34 & .16 & .79 & .56 & .38 & .42 & .29 & .23 \\
\hline N3: Depression & .87 & .58 & .26 & .86 & .52 & .26 & .59 & .45 & .35 \\
\hline N4: Self-Consciousness & .79 & .45 & .22 & .78 & .55 & .25 & .55 & .37 & .34 \\
\hline N5: Impulsiveness & .62 & .64 & .44 & .63 & .50 & .30 & .40 & .30 & .30 \\
\hline N6: Vulnerability & .79 & .59 & .37 & .83 & .66 & .48 & .52 & .41 & .33 \\
\hline E1: Warmth & .76 & .58 & .46 & .80 & .58 & .45 & .63 & .42 & .42 \\
\hline E2: Gregariousness & .79 & .29 & .17 & .82 & .45 & .25 & .61 & .38 & .45 \\
\hline E3: Assertiveness & .84 & .64 & .42 & .85 & .64 & .48 & .65 & .40 & .40 \\
\hline E4: Activity & .68 & .48 & .20 & .76 & .53 & .40 & .51 & .36 & .41 \\
\hline E5: Excitement Seeking & .57 & .25 & .11 & .63 & .31 & .20 & .65 & .25 & .23 \\
\hline E6: Positive Emotions & .79 & .59 & .44 & .81 & .56 & .50 & .62 & .52 & .52 \\
\hline 01: Fantasy & .81 & .55 & .28 & .82 & .52 & .32 & .46 & .36 & .33 \\
\hline 02: Aesthetics & .78 & .56 & .35 & .79 & .67 & .45 & .59 & .54 & .45 \\
\hline 03: Feelings & .74 & .55 & .31 & .76 & .64 & .41 & .48 & .44 & .35 \\
\hline 04: Actions & .58 & .44 & .28 & .64 & .37 & .25 & .51 & .28 & .28 \\
\hline 05: Ideas & .80 & .56 & .38 & .83 & .67 & .58 & .64 & .48 & .49 \\
\hline 06: Values & .47 & .44 & .19 & .45 & .45 & .25 & .39 & .26 & .25 \\
\hline A1: Trust & .82 & .45 & .28 & .86 & .56 & .42 & .49 & .42 & .46 \\
\hline A2: Straightforwardness & .73 & .56 & .41 & .74 & .53 & .42 & .52 & .41 & .41 \\
\hline A3: Altruism & .69 & .55 & .42 & .71 & .62 & .56 & .56 & .42 & .42 \\
\hline A4: Compliance & .65 & .56 & .34 & .79 & .66 & .52 & 61 & .41 & .46 \\
\hline A5: Modesty & .77 & .59 & .45 & .74 & .56 & .38 & .44 & .41 & .32 \\
\hline A6: Tender-Mindedness & .67 & .48 & .26 & .71 & .48 & .28 & .50 & .37 & .38 \\
\hline C1: Competence & .58 & .50 & .37 & .62 & .69 & .55 & .47 & .36 & .29 \\
\hline C2: Order & 68 & .40 & .19 & .72 & .38 & .20 & 67 & .32 & .31 \\
\hline C3: Dutifulness & .62 & .52 & .35 & .67 & .59 & .42 & .33 & .30 & .30 \\
\hline C4: Achievement Striving & .73 & .66 & .27 & .68 & .45 & .32 & .53 & .47 & .37 \\
\hline C5: Self-Discipline & .80 & .62 & .36 & .83 & .71 & .50 & .45 & .42 & .44 \\
\hline C6: Deliberation & .77 & .59 & .48 & .79 & .72 & .52 & .47 & .47 & .41 \\
\hline \multicolumn{10}{|l|}{ NEO-PI-R factors } \\
\hline Neuroticism & .85 & .64 & .38 & .85 & .71 & .37 & .61 & .40 & .35 \\
\hline Extraversion & .69 & .64 & .48 & .80 & .66 & .53 & .67 & .41 & .52 \\
\hline Openness to experience & .71 & .64 & .38 & .76 & .74 & .59 & .62 & .48 & .38 \\
\hline Agreeableness & .75 & .69 & .55 & .82 & .74 & .69 & .67 & .45 & .50 \\
\hline Conscientiousness & .79 & .74 & .50 & .80 & .74 & .53 & .57 & .45 & .44 \\
\hline
\end{tabular}

Notes. $N=152$. 


\section{PERSONALITY AND CHARACTER}

Table 2

Cronbach's alpha and $R^{2}$ between the VIA-IS scales and factors and the NEO-PI-R facets and factors in Self- and Peer-Reports, and Convergent and Discriminant Correlations across Selfand Peer-Reports

\begin{tabular}{|c|c|c|c|c|c|c|c|c|c|}
\hline & \multicolumn{3}{|c|}{ Self-reports } & \multicolumn{3}{|c|}{ Peer-reports } & \multicolumn{3}{|c|}{ Self $\times$ peer-reports } \\
\hline & Alpha & $\begin{array}{l}\text { NEO } \\
\text { facets }\end{array}$ & $\begin{array}{l}\text { NEO } \\
\text { factors }\end{array}$ & Alpha & $\begin{array}{l}\text { NEO } \\
\text { facets }\end{array}$ & $\begin{array}{l}\text { NEO } \\
\text { factors }\end{array}$ & $\begin{array}{l}\text { Conver- } \\
\text { gence }\end{array}$ & $\begin{array}{l}\text { NEO } \\
\text { facets }\end{array}$ & $\begin{array}{l}\text { NEO } \\
\text { factors }\end{array}$ \\
\hline \multicolumn{10}{|l|}{ VIA-IS scales } \\
\hline Creativity & .83 & .53 & .44 & .84 & .50 & .40 & .49 & .34 & .36 \\
\hline Curiosity & .74 & .52 & .32 & .78 & .72 & .58 & .41 & .36 & .32 \\
\hline Judgment & .81 & .66 & .38 & .84 & .74 & .50 & .48 & .43 & .26 \\
\hline Love of learning & .80 & .48 & .25 & .85 & .69 & .55 & .58 & .48 & .40 \\
\hline Perspective & .71 & .48 & .28 & .77 & .55 & .40 & .29 & .36 & .30 \\
\hline Bravery & .70 & .50 & .32 & .75 & .49 & .26 & .44 & .39 & .33 \\
\hline Perseverance & .83 & .71 & .56 & .85 & .69 & .53 & .50 & .47 & .45 \\
\hline Honesty & .69 & .58 & .41 & .70 & .56 & .36 & .26 & .33 & .34 \\
\hline Zest & .71 & .61 & .50 & .72 & .66 & .48 & .42 & .41 & .41 \\
\hline Love & .66 & .36 & .18 & .74 & .50 & .20 & .40 & .38 & .28 \\
\hline Kindness & .71 & .48 & .29 & .76 & .59 & .48 & .49 & .42 & .34 \\
\hline Social intelligence & .70 & .56 & .32 & .75 & .58 & .42 & .34 & .41 & .36 \\
\hline Teamwork & .76 & .50 & .31 & .74 & .49 & .41 & .39 & .42 & .33 \\
\hline Fairness & .77 & .61 & .45 & .82 & .66 & .59 & .40 & .41 & .45 \\
\hline Leadership & .68 & .49 & .32 & .82 & .55 & .35 & .29 & .31 & .24 \\
\hline Forgiveness & .78 & .59 & .42 & .83 & .66 & .52 & .40 & .42 & .43 \\
\hline Humility & .75 & .69 & .40 & .79 & .62 & .45 & .40 & .41 & .37 \\
\hline Prudence & .74 & .69 & .58 & .71 & .67 & .56 & .52 & .47 & .39 \\
\hline Self-regulation & .72 & .62 & .37 & .75 & .64 & .48 & .41 & .36 & .31 \\
\hline Appreciation & .73 & .62 & .48 & .81 & .64 & .46 & .59 & .54 & .48 \\
\hline Gratitude & .75 & .49 & .34 & .79 & .50 & .30 & .48 & .40 & .28 \\
\hline Hope & .71 & .53 & .36 & .80 & .64 & .44 & .46 & .45 & .40 \\
\hline Humor & .84 & .66 & .31 & .88 & .62 & .45 & .52 & .52 & .35 \\
\hline Spirituality & .89 & .38 & .13 & .89 & .40 & .12 & .77 & .31 & .26 \\
\hline \multicolumn{10}{|l|}{ VIA-IS factors } \\
\hline Restraint & .80 & .72 & .62 & .81 & .72 & .62 & .43 & .44 & .44 \\
\hline Emotional & .84 & .66 & .38 & .86 & .74 & .62 & .49 & .52 & .52 \\
\hline Interpersonal & .83 & .64 & .46 & .82 & .76 & .64 & .37 & .46 & .50 \\
\hline Intellectual & .75 & .67 & .49 & .83 & .76 & .59 & .46 & .49 & .38 \\
\hline Theological & .68 & .52 & .31 & .74 & .56 & .25 & .62 & .45 & .34 \\
\hline
\end{tabular}

Notes. $N=152$; Appreciation $=$ appreciation of beauty and excellence 


\section{Discussion}

The aim of the present study was to replicate previous findings on the relationship between personality and character and to extend them to novel methods (peer-reports), instruments (VIA-IS and NEO-PI-R) and levels of analysis (facets/scales and factors/domains). First, the previously found large predictions of the character strengths by the FFM personality domains and facets (Dametto, \& Porto Noronha, 2021; Macdonald et al., 2007; McGrath et al., 2020; Noftle et al., 2011) were replicated in both self- and peer-reports. The overlap was notably larger when the facets/scales were used as predictors than when the domains/factors were employed. This supports the incremental validity of lower-level, specific constructs (e.g., Anglim \& Grant, 2014), even when the outcomes to be predicted were more abstract in nature (i.e., domains/factors). Personality explained approximately as much variance in character as character did explain in personality. Hence, the overlap between the two standard inventories was mutual, and both seem to assess relevant variance for each domain of personality and character.

Despite the large overlap between the NEO-PI-R and VIA-IS, they could be empirically distinguished, with the exception of three personality facets. N5 Impulsiveness and $\mathrm{C} 1$ Competence shared large amounts of variance (64\% and $69 \%$, respectively) with the VIA scales, indicating that these facets were saturated with character-relevant variance. For N5 Impulsiveness, these were mostly related to the temperance strengths (prudence and selfregulation), and for $\mathrm{C} 1$ Competence mostly related to wisdom strengths (judgment, perspective) as well as perseverance. For the third facet, O6 Values, the overlap with character was comparably smaller (45\%). However, this facet's reliability was very low (.47 in self- and .45 in peer-reports), indicating more a measurement issue than high saturation by character. None of the VIA scales and factors was sufficiently explained by either the NEO- 


\section{PERSONALITY AND CHARACTER}

PI-R facets or domains, indicating that they captured surplus variance that went beyond devaluated personality.

The MTMM analyses supported the convergent and discriminant validity of all NEOPI-R facet and domain scores in comparison to the VIA-IS across self- and peer-reports. By contrast, convergent validity was low for three VIA-IS scales (perspective, honesty, and leadership), which is in line with the findings by Ruch et al. (2010). Discriminant validity was not supported for eight VIA-IS scales, of which most belonged to interpersonal strengths. They related more strongly to agreeableness (facets and domain) than to their corresponding score, and hence seem to represent a positively evaluated version of agreeableness. Furthermore, 4/5 VIA factors lacked discriminant validity to the NEO-PI-R facets (and 3 also to the NEO-PI-R domains). This indicates that character and personality were insufficiently distinguished when comparing people's introspective judgements (self-reports) and other people's perception of their related behavior. This suggests that the VIA factors (except for theological strengths) and interpersonal strengths seem somewhat redundant with personality when compared across self- and peer-reports. Although the present study cannot uncover the nature of these findings, the self-other knowledge asymmetry model (Vazire, 2010) suggests that observability and evaluativeness could be relevant factors that contribute to the lower construct validity of the VIA-IS in the MTMM analyses. Future studies could investigate which cues people use to judge character in others and who might be best at judging character, as has been done for personality traits (e.g., Borkenau et al., 2004).

The primary impact of the present work is a more comprehensive study of the overlap between personality and character. Taken together, the results generally supported that personality and character are distinct, although largely overlapping constructs. The highest overlaps and some redundancies were found when using the lowest levels of abstraction (i.e., scales and facets) as predictors and for interpersonal strengths, which consist of kindness, teamwork, fairness, leadership, forgiveness, and humility (which strongly overlapped with 


\section{PERSONALITY AND CHARACTER}

agreeableness). Also, 4/5 VIA factors lacked discriminant validity with personality, showing that the surplus variance that can be explained by the character approach is located at the level of character strengths, which should be used as the preferred level of analyses in research and applications. Overall, the partial overlap between character and personality goes against Allport's (1927) strict differentiation and shows that personality is more than character devaluated, and character is more than personality evaluated. This finding also resonates with Allport's later, more unifying approaches to traits that can include ethical ideals (Allport \& Odbert, 1936, p. 28).

\section{Limitations and Implications for Future Research and Applications}

Despite its methodological strengths, our study has several limitations. Some limitations are related to the rather small sample size. Accordingly, only observed variables could be used in analyses. Future studies should explore the relationship between personality and character using larger samples that allow applying latent analyses. Encouragingly, McGrath et al. (2020) found similar results for both observed and latent analyses, which suggests that the difference between observed and latent modeling might be small. Further, for effect estimation, larger sample sizes are recommended (Schönbrodt \& Perugini, 2013); for example, Cronbach`s alpha being smaller than $R^{2}$ could be due to the small sample. We, therefore, encourage future studies on this topic with a larger samples. Furthermore, we used Cronbach`s alpha, which could underestimate reliability substantially. Future studies could adopt other reliability indicators, such as test-retest reliability or McDonald`s omega.

A further limitation is that we did not explore the criterion and incremental validity of the constructs. Thus, it is unclear how the observed differences, or the "gap" between personality and character, would impact the nomological network of both personality and character. Previous studies suggested that character strengths can incrementally predict certain outcomes beyond the FFM traits and facets (McGrath et al., 2020; Noftle et al., 2011). Nevertheless, a more comprehensive analysis of how personality and character can predict 


\section{PERSONALITY AND CHARACTER}

positive and moral outcomes (in line with the conceptualization of the character strengths) is yet missing and should be undertaken in future research. Furthermore, a more comprehensive study with multiple operationalizations of personality (e.g. BFI-2) and character (e.g. CSRF) would be desirable to determine whether the overlap between the constructs is lower than within each construct.

Another limitation is the specificity of the sample, as we used personal contacts for recruitment. Further, we only employed one peer-report for each target. This might have contributed to lower self-peer convergence, distorting the interpretation of both convergent and discriminant validity. Ideally, future studies would collect three peer-reports for each target to yield a better convergence and to allow for more sophisticated analyses of MTMM data, such as combining multilevel modeling and confirmatory factor analyses (e.g., Carretero-Dios et al., 2011). Furthermore, the order of questionnaires was not randomized, leading to potential order effects when answering the items. While our investigation focused on the empirical relationships between personality and character, a recent study supported our findings from a conceptual and content-analysis perspective (Aluri \& Li, 2022). Future research could adopt an interdisciplinary approach for a broader examination of the association between personality and character.

\section{Conclusions}

The aim of the present study was to comprehensively examine the relationship between character (i.e., the 24 VIA-IS strengths) and personality (i.e., the 30 facets and five domains of the NEO-PI-R). Previous results on the overlap between character and personality were replicated and extended by analyses of self- and peer-reports. The results supported the assumption that personality and character, although strongly related, are two distinct constructs, or 'distant relatives'. Hence, the study of both 'neutral' and positively valued personality traits is needed to broaden our knowledge on individual differences. 
PERSONALITY AND CHARACTER

\section{References}

Allport, G.W. (1921). Personality and character. Psychological Bulletin, 18(9), 441-455. https://doi.org/10.1037/h0066265

Allport, G.W. (1927). Concepts of trait and personality. Psychological Bulletin, 24, 284-293. https://doi.org/10.1037/h0073629

Allport, G.W., \& Odbert, H. (1936). Trait-names: A psycho-lexical study. No. 211. Psychological Review Monographs.

Aluri, J. T., \& Li, K. C. (2022). Personality and character: A comparative qualitative analysis of trait descriptions in NEO-PI-3 and character strengths and virtues. Journal of Happiness Studies. Advance online publication. https://doi.org/10.1007/s10902-022$\underline{00535-0}$

Anglim, J., \& Grant, S.L. (2014). Incremental criterion prediction of personality facets over factors: Obtaining unbiased estimates and confidence intervals. Journal of Research in Personality, 53, 148-157. https://doi.org/10.1016/j.jrp.2014.10.005

Borkenau, P., Mauer, N., Riemann, R., Spinath, F.M., \& Angleitner, A. (2004). Thin slices of behavior as cues of personality and intelligence. Journal of Personality and Social Psychology, 86, 599-614. https://doi.org/10.1037/0022-3514.86.4.599

Campbell, D.T., \& Fiske, D.W. (1959). Convergent and discriminant validation by the multitrait-multimethod matrix. Psychological Bulletin, 56, 81-105. https://doi.org/10.1037/h0046016

Carretero-Dios, H., Eid, M., \& Ruch, W. (2011). Analyzing multitrait-mulitmethod data with multilevel confirmatory factor analysis: An application to the validation of the StateTrait Cheerfulness Inventory. Journal of Research in Personality, 45, 153-164. https://doi.org/10.1016/j.jrp.2010.12.007 


\section{PERSONALITY AND CHARACTER}

Costa Jr., P.T. \& McCrae, R.R. (1992). Revised NEO Personality Inventory (NEO-PI-R) and NEO Five Factor Inventory. Professional manual. Psychological Assessment Resources.

Costa Jr, P.T., McCrae, R.R., \& Löckenhoff, C.E. (2019). Personality across the life span. Annual Review of Psychology, 70, 423-448. https://doi.org/10.1146/annurev-psych010418-103244

Dametto, D.M., \& Porto Noronha, A.P. (2021). Study between personality traits and character strengths in adolescents. Current Psychology, 40, 2067-2072. https://doi.org/10.1007/s12144-019-0146-2

Gignac, G.E., \& Szodorai, E.T. (2016). Effect size guidelines for individual differences researchers. Personality and Individual Differences, 102, 74-78. https://doi.org/10.1016/j.paid.2016.06.069

Macdonald, C., Bore, M., \& Munro, D. (2008). Values in Action Scale and the Big 5: An empirical indication of structure. Journal of Research in Personality, 42, 787-799. https://doi.org/10.1016/j.jrp.2007.10.003

McCrae, R.R., \& Costa Jr, P.T. (1999). A five-factor theory of personality. In O. P. John, R. W. Robins, \& L. A. Pervin (Eds.), Handbook of personality: Theory and research ( $3^{\text {rd }}$ ed.) (pp. 139-153). Guilford Press.

McGrath, R.E. (2014). Scale-and item-level factor analyses of the VIA Inventory of Strengths. Assessment, 21, 4-14. https://doi.org/10.1177/1073191112450612

McGrath, R.E., Hall-Simmonds, A., \& Goldberg, L.R. (2020). Are measures of character and personality distinct? Evidence from observed-score and true-score analyses. Assessment, 27, 117-135. https://doi.org/10.1177/1073191117738047

Nicholson, I.A.M. (1998). Gordon Allport, character, and the "culture of personality". History of Psychology, 1(1), 52-68. 


\section{PERSONALITY AND CHARACTER}

Noftle, E.E., Schnitker, S.A., \& Robins, R.W. (2011). Character and personality: Connections between positive psychology and personality psychology. In K.M. Sheldon, T.B. Kashdan, \& M.F. Steger (Eds.), Designing positive psychology: Taking stock and moving forward (pp. 207-227). Oxford University Press.

Ostendorf, F. \& Angleitner, A. (2004). NEO-PI-R. NEO-Persönlichkeitsinventar nach Costa und McCrae. Revidierte Fassung. Manual. [NEO-PI-R. The Costa and McCrae `s NEO-personality inventory. Revised version. The manual.] Hogrefe.

Ozer, D. J., \& Benet-Martínez, V. (2006). Personality and the prediction of consequential outcomes. Annual Review of Psychology, 57(1), 401-421. https://doi.org/10.1146/annurev.psych.57.102904.190127

Peterson, C., Park, N., \& Seligman, M.E.P. (2005). Assessment of character strengths. In G.P. Koocher, J.C. Norcross, \& S.S. Hill III (Eds.), Psychologists' desk reference (2nd ed., pp. 93-98). Oxford University Press.

Rhoads, C.H. (2012). Problems with tests of the missingness mechanism in quantitative policy studies. Statistics, Politics, and Policy, 3(1), 1-24. https://doi.org/10.1515/2151$\underline{7509.1012}$

Ruch, W., Proyer, R.T., Harzer, C., Park, N., Peterson, C., \& Seligman, M.E.P. (2010). Adaptation and validation of the German version of the Values in Action Inventory of Strengths (VIA-IS) and the development of a peer-rating form. Journal of Individual Differences, 31, 138-149. https://doi.org/10.1027/1614-0001/a000022

Schönbrodt, F. D., \& Perugini, M. (2013). At what sample size do correlations stabilize? Journal of Research in Personality, 47(5), 609-612. https://doi.org/10.1016/j.jrp.2013.05.009

Stahlmann, A.G., \& Ruch, W. (2020). Scrutinizing the criteria for character strengths: Laypersons assert that every strength is positively morally valued, even in the absence 
PERSONALITY AND CHARACTER

of tangible outcomes. Frontiers in Psychology, 11: 591028.

https://doi.org/10.3389/fpsyg.2020.591028

Seligman, M.E.P., \& Csikszentmihalyi, M. (2000). Positive psychology: An introduction. American Psychologist, 55, 5-14. https://doi.org/10.1037//0003-066X.55.1.5

Vazire, S. (2010). Who knows what about a person? The self-other knowledge asymmetry (SOKA) model. Journal of Personality and Social Psychology, 98, 281-300. https://doi.org/10.1037/a0017908 